\title{
Molecularly imprinted poly(2-oxazoline) based on crosslinking by direct amidation of methyl ester side chains
}

Michał Cegłowski* and Richard Hoogenboom*

Supramolecular Chemistry Group, Centre of Macromolecular Chemistry (CMaC), Department of Organic and Macromolecular Chemistry, Ghent University, Krijgslaan 281 S4, B-9000 Ghent, Belgium

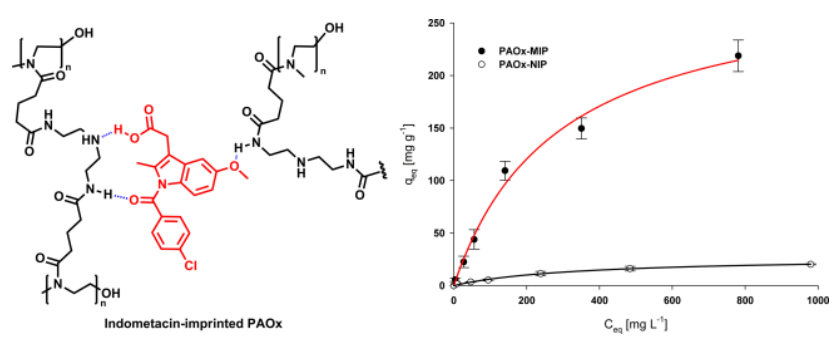

for Table of Contents use only

Keywords: molecularly imprinted polymers; polyoxazoline; adsorption; drug release

\begin{abstract}
Molecularly imprinted polymers (MIPs) are tailor-made synthetic materials possessing memory of their molecular templates that have found numerous applications in separation science, drug delivery and catalysis. Here, we report the development of a MIP based on poly(2-oxazoline)s. The crosslinked imprinted polymer was obtained by reacting a short-chain poly(2-oxazoline) with methyl ester side chains with diethylenetriamine in the presence of indometacin as template. The crosslinker diethylenetriamine simultaneously acted as crosslinker and to interact with the indometacin template. The influence of several parameters on indometacin adsorption such as
\end{abstract}


initial concentration, contact time, and temperature as well as reusability of the MIPs and kinetics of indometacin release have been investigated. The maximum amount of indometacin bonded reached $293 \mathrm{mg} \mathrm{g}^{-1}$ for imprinted polymer vs. $25 \mathrm{mg} \mathrm{g}^{-1}$ for non-imprinted polymer. This result clearly indicates that molecularly imprinted poly(2-oxazoline)s possess a large potential for developing new MIPs due to their high imprinting properties.

\section{Introduction}

Molecularly imprinted polymers (MIPs) are polymers possessing antibody-like affinity towards particular molecules. ${ }^{1-3}$ The most common synthesis of MIPs involves copolymerization of a mixture of functional monomers and cross-linkers in the presence of template molecules. The functional monomers are responsible for forming intermolecular interactions with the template molecules, whereas the cross-linkers form the molecular scaffold around the template molecules during polymerization. An alternative method for the preparation of MIPs is by crosslinking of preformed polymers in the presence of the template in a so-called post-polymerization modification reaction. ${ }^{4-6}$ In this approach, the prepolymer can contain functional groups that interact with the template while additional interactive groups may be present in the crosslinker. Removal of the template molecules after synthesis allows to obtain MIPs that are selective towards the template molecules. The reason of the high selectivity is the fact that MIPs possess cavities that are complementary to the template molecules by size, shape and presence of particular functional groups. The advantage of MIPs over natural antibodies is their high thermal and chemical stability, excellent reusability and easy, low-cost synthesis. ${ }^{7}$ The MIPs have found numerous application in solid-phase extraction, ${ }^{8-10}$ catalysis,,${ }^{11-13}$ as sensors, ${ }^{14-16}$ and in drug delivery. ${ }^{17-20}$

Drug delivery is the process or method that allows to transport drugs into the body to achieve the desired therapeutic effect. ${ }^{21}$ To maximize the efficiency and safety of medicines, drug delivery 
systems should be able to regulate the release rate of a medicine to maintain its concentration in the therapeutic window and/or release it to a specific site. ${ }^{22,23}$ Based on their unique properties MIPs seem to be perfectly designed for controlled drug delivery, as the strength of their interactions with the template molecules can be tuned by changing the composition of functional monomers and cross-linkers, thereby enabling control over the drug release rate. Up to now, most MIPs are synthesized using methacrylates or vinyl monomers, which show limited hydrophilicity and low biocompatibility. ${ }^{24}$ These drawbacks are the reason to develop new types of MIPs which can be used as drug delivery systems. ${ }^{25}$

Poly(2-oxazoline)s ${ }^{26-28}$ represent a group of polymers which are obtained by cationic ring-opening polymerization of 2-oxazolines. ${ }^{29}$ The properties of the final polymer may be altered by changing the side chain of 2-oxazoline monomer or by copolymerizing various monomers. ${ }^{30}$ In recent years, poly(2-oxazoline)s have received much attention due to their biocompatibility, stealth behavior and high synthetic versatility. ${ }^{31-33}$ As a result, they have found numerous biomedical applications such as drug delivery, ${ }^{34-36}$ preparation of micelles, ${ }^{37-39}$ drug conjugates, ${ }^{40-42}$ non-fouling coatings, ${ }^{43-45}$ gene delivery, ${ }^{46-48}$ or preparation of hemostatic materials. ${ }^{49}$

In this work, we report the synthesis of molecularly imprinted poly(2-oxazoline)s and their application in sustained release of the anti-inflammatory drug indometacin. To the best of our knowledge, this is the first study describing the synthesis of molecularly imprinted poly(2oxazoline)s. The limitations of cationic ring-opening polymerization of 2-oxazolines, particularly necessity to avoid presence of any nucleophilic groups, makes it challenging to imprint poly(2oxazoline)s during the polymerization. To overcome this limitation, we have prepared MIPs by crosslinking of short poly(2-oxazoline) prepolymers possessing methyl ester groups in their side chains using a direct amidation reaction with diethylenetriamine in the presence of indometacin as a template molecule. The crosslinker simultaneously acts as a functional monomer as it possesses 
a free amine group which can interact with the template molecule. Within this paper, we present the physicochemical properties of the obtained MIPs as well as its ability for sustained release of indometacin.

\section{Experimental}

\subsection{Materials and chemicals}

Methyl tosylate (MeOTs) was distilled and stored under argon. Indomethacin were obtained from TCI Europe. Glutaric anhydride, thionyl chloride, 2-chloroethylamine hydrochloride, diethylenetriamine, triethylamine, sodium chloride, thionyl chloride anhydrous sodium sulfate, and anhydrous sodium carbonate were obtained from Sigma-Aldrich and used as received. Methanol, chloroform, dimethylformamide, and dichloromethane (HPLC grade) were obtained from SigmaAldrich.

\subsection{Instruments}

Nuclear magnetic resonance (NMR) spectra were recorded on a Bruker DMC300 (300 MHz for $1 \mathrm{H}, 75 \mathrm{MHz}$ for $13 \mathrm{C}$ ). UV-vis measurements were performed on a Varian Cary 100 Bio spectrophotometer using $1 \mathrm{~cm}$ quartz cuvettes. Polymerization was conducted in a Biotage Initiator Microwave System with Robot Sixty utilizing capped reaction vials. Scanning electron microscopy (SEM) images were obtained on a FEI Quanta 200F Microscope. All samples were placed on a carbon tape and covered with gold layer using sputter coating prior to analysis. The FTIR spectra were recorded on a Perkin Elmer Spectrum 1000 FTIR spectrometer in the $600-4000 \mathrm{~cm}^{-1}$ range using attenuated total reflectance (ATR) mode. Thermal data were obtained by using a Mettler 
Toledo TGA/SDTA 851e. The thermal stability of the materials was investigated by thermogravimetric analysis in nitrogen stream at a heating rate of $10^{\circ} \mathrm{C} \mathrm{min}^{-1}$.

\subsection{Synthesis of 2-methoxycarbonylpropyl-2-oxazoline (C3MestOx)}

Four step synthesis of C3MestOx monomer was described in our previous work. ${ }^{50}$ Briefly, the sythesis involves reaction of glutaric anhydride with methanol to form monomethyl glutarate, which can be subsequetnly reacted with thionyl chloride to obtain glutaric acid monomethyl ester chloride. The obtained product is reacted with 2-chloroethylamine hydrochloride to form $\mathrm{C} 3 \mathrm{MestOx}$ precursor. The last reaction is a ring closure reaction that occurs between $\mathrm{C} 3 \mathrm{MestOx}$ precursor and anhydrous sodium carbonate. The final C3MestOx has to be distilled over barium oxide under vacuum before further use.

\subsection{Polymerization of $\mathrm{C} 3 \mathrm{MestOx}$}

C3MestOx monomer $(24 \mathrm{mmol})$, MeOTs initiator $(0.48 \mathrm{mmol})$ and acetonitrile $(1.69 \mathrm{~mL})$ were mixed under inert atmosphere in a microwave vial. The solution was polymerized in the microwave at $140^{\circ} \mathrm{C}$ for $450 \mathrm{~s}$. When finished, piperidine $(0.2 \mathrm{~mL})$ was added to terminate the polymer and the solution was stirred overnight at room temperature. The poly $(\mathrm{C} 3 \mathrm{MestOx})$ obtained $(\mathrm{DP}=50)$ was precipitated by pouring the solution into cold diethyl ether. After removing all solvent the polymer was obtained as a sticky oil. ${ }^{1} \mathrm{H}$ NMR $\left(400 \mathrm{MHz} \mathrm{CDCl}_{3}\right): \delta=3.65$ (br, $\left.-\mathrm{COO}-\mathrm{CH}_{3}\right), 3.58-3.33$ (br, -N-CH${ }_{2}-\mathrm{CH}_{2}-\mathrm{N}-$ ), 2.49-2.22 (br, $-\mathrm{CH}_{2}-\mathrm{CH}_{2}-\mathrm{CH}_{2}-$ ), 1.98-1.75 (br, $-\mathrm{CH}_{2}-\mathrm{CH}_{2}-\mathrm{CH}_{2}-$ ).

\subsection{Poly(2-oxazoline) MIPs synthesis}

Poly(C3MestOx) (2.3363 g), diethylenetriamine $(6.745 \mathrm{mmol})$ and indometacin $(1.686 \mathrm{mmol})$ were dissolved in chloroform $(10 \mathrm{~mL})$ in a round bottom flask. The flask was placed in an oil bath 
at $85^{\circ} \mathrm{C}$ under a slight argon stream. After around $30 \mathrm{~min}$. when most of the chloroform was evaporated, the mixture formed a rigid polymer. The reaction was continued overnight to allow full cross-linking. The polymer obtained (PAOx-MIP) was grinded, sieved using 40-mesh sieve and dialyzed against $\mathrm{MeOH} / \mathrm{NH}_{3}(\mathrm{aq})(95: 5)$ three times and with $\mathrm{MeOH}$ two times to remove the template molecules. Afterwards, it was dried under vacuum at $40^{\circ} \mathrm{C}$ to remove the solvent. A non-imprinted polymer (PAOx-NIP) was synthesized similarly to the MIPs but without the use of the indometacin template.

\subsection{Adsorption experiments}

The adsorption of indometacin on the PAOx-MIP and PAOx-NIP was examined using batch experiments. To prepare adsorption isotherms, a series of samples containing $10 \mathrm{mg}$ of PAOx-MIP or PAOx-NIP were equilibrated for $48 \mathrm{~h}$ with $10 \mathrm{~mL}$ chloroform solution containing various concentrations of indometacin $\left(0.01 \mathrm{mg} \mathrm{mL}^{-1}-2 \mathrm{mg} \mathrm{mL}^{-1}\right)$. The concentration of indometacin before and after adsorption was measured using UV-vis spectrophotometer. The amount of indometacin adsorbed $\left(\mathrm{q}_{\mathrm{eq}} ; \mathrm{mg} \mathrm{g}^{-1}\right)$ was calculated using the following equation:

$$
q_{e q}=\frac{\left(C_{0}-C_{e q}\right) V}{m}
$$

where $\mathrm{C}_{0}$ and $\mathrm{C}_{\mathrm{eq}}$ are the initial and equilibrium concentrations $\left(\mathrm{mg} \mathrm{mL}^{-1}\right), \mathrm{m}$ is the mass of the polymer $(\mathrm{g})$ and $\mathrm{V}$ is the solution volume $(\mathrm{mL})$. All measurement were repeated in triplicate.

For the adsorption kinetic studies $50 \mathrm{mg}$ of PAOx-MIP or PAOx-NIP and $50 \mathrm{~mL}$ of indometacin chloroform solution at the initial concentration of $0.25 \mathrm{mg} \mathrm{mL}^{-1}$ were stirred at room temperature. The concentration of indometacin was measured at present time intervals using UV-vis spectrophotometer. The amount of indometacin adsorbed at time $\mathrm{t}\left(\mathrm{q}_{\mathrm{t}} ; \mathrm{mg} \mathrm{g}^{-1}\right)$ was calculated from: 


$$
q_{t}=\frac{\left(C_{0}-C_{t}\right) V}{m}
$$

where $\mathrm{C}_{\mathrm{t}}$ is the indometacin concentration at time $\mathrm{t}(\mathrm{h})$.

Thermodynamic studies were performed for the sets of samples containing $20 \mathrm{mg}$ of PAOx-MIP or PAOx-NIP and $10 \mathrm{~mL}$ of indometacin chloroform solution with the initial concentration of 0.25 $\mathrm{mg} \mathrm{mL}{ }^{-1}$. The experiments were performed under $25,33,40$, and $60^{\circ} \mathrm{C}$. Other experimental details were as for isotherms determination.

Sorption/desorption experiments were performed in $48 \mathrm{~h}$ intervals for the sets of samples containing $20 \mathrm{mg}$ of of PAOx-MIP or PAOx-NIP and $10 \mathrm{~mL}$ of indometacin chloroform solution with the initial concentration of $0.25 \mathrm{mg} \mathrm{mL}^{-1}$. After each adsorption the liquid phase was collected and the polymer was washed with $\mathrm{MeOH} / \mathrm{NH}_{3}$ (aq) (95:5) solution, followed by $\mathrm{MeOH}$ and dried. The concentration of indometacin before and after adsorption was measured using UV-vis spectrophotometer. To test the reusability of the polymers, this adsorption/desorption cycle was repeated five times with using the same adsorbent.

\subsection{In vitro drug release studies}

For the in vitro release studies $50 \mathrm{mg}$ of PAOx-MIP containing indometacin were immersed in in phosphate buffered saline (PBS, pH 7.4) mixed with EtOH (70:30), and stirred at $37^{\circ} \mathrm{C}$. The second set of samples was immersed in $\mathrm{HCl}-\mathrm{KCl}$ buffer (simulated gastro-intestinal conditions, $\mathrm{pH} \mathrm{2.0)}$ mixed with $\mathrm{EtOH}(70: 30)$, and stirred at $37^{\circ} \mathrm{C}$. The concentration of indometacin was measured at present time intervals using UV-vis spectrophotometer. Total amounts of the drug released $\left(\mathrm{F}_{\mathrm{T}}\right.$; $\mathrm{mg}$ ) were calculated as follows:

$$
F_{T}=V_{m} C_{t}
$$

where $\mathrm{V}_{\mathrm{m}}(\mathrm{mL})$ and $\mathrm{C}_{\mathrm{t}}\left(\mathrm{mg} \mathrm{mL}^{-1}\right)$ are volume and indometacin concentration at time $\mathrm{t}$. 
The drug release data were fitted to different kinetic models. The data were analyzed using zero order (4), first order (5), Higuchi (6), and Hixon-Crowell (7) mathematical models.

$$
\begin{aligned}
& F_{t}=k_{o} t \\
& F_{t}=1-e^{-k_{1} t} \\
& F_{t}=k_{H} \sqrt{t} \\
& \sqrt[3]{F_{0}}-\sqrt[3]{F_{t}}=k_{H C} t
\end{aligned}
$$

where $F_{t}$ is the fraction of the drug released at time $t, F_{0}$ is the initial amount of the drug in the polymer, $\mathrm{k}_{0}, \mathrm{k}_{1}, \mathrm{k}_{\mathrm{H}}$, and $\mathrm{k}_{\mathrm{HC}}$ are the release constants of the respective equations.

\section{Results and discussion}

\subsection{Polymer synthesis and characterization}

The poly(2-oxazoline) based MIP was synthesized using poly(2-methoxycarbonylpropyl-2oxazoline $)(\operatorname{poly}(\mathrm{C} 3 \mathrm{MestOx}))$ of $\mathrm{DP}=50$ as prepolymer, which is a short-chain poly(2-oxazoline) possessing methyl ester groups in the side chain. This polymer can be easily functionalized by a direct amidation reaction in order to produce more complex structures and introduce additional functionalities. ${ }^{51}$ The reaction with diethylenetriamine in the presence of the template indometacin resulted in a highly cross-linked molecularly imprinted poly(2-oxazoline) (Figure 1). The amount of diethylenetriamine used for the reaction was designed in such a way that two-thirds of the amine groups, presumably mostly the primary amine groups, could react with the poly(C3MestOx) methyl ester groups to form the highly crosslinked polymer scaffold, whereas the remaining amine groups are responsible for creating strong interactions with the template molecules. As a result, diethylenetriamine is simultaneously performing the role of a cross-linker and a functional interacting moiety. 


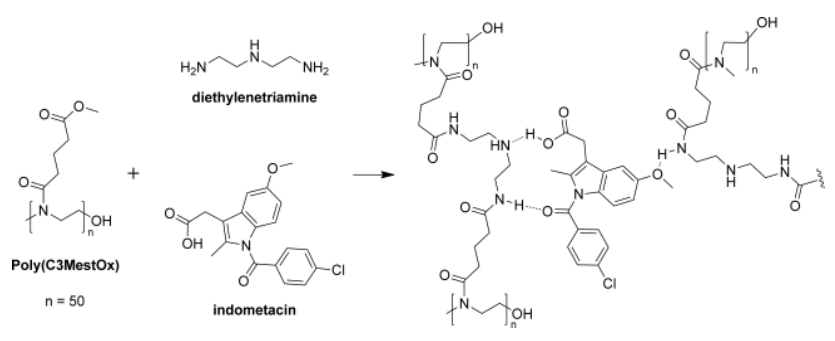

Figure 1. Scheme of synthesis of PAOx-MIP with its proposed structure.

The FT-IR absorbance spectra of as obtained, drug loaded, poly(2-oxazoline) MIP (PAOx-MIP), drug unloaded PAOx-MIP and the corresponding poly(2-oxazoline) non-imprinted polymer (PAOx-NIP), that was prepared under the same conditions in absence of the template, are presented in Figure 2. All three polymers display similar characteristic peaks in the IR spectra, indicating that the main structure of both polymers is identical. All spectra show absorption bands at $3282 \mathrm{~cm}^{-1}(v$ $\mathrm{N}-\mathrm{H}$, broad band), $2930 \mathrm{~cm}^{-1}(v \mathrm{C}-\mathrm{H}), 1730 \mathrm{~cm}^{-1}(v \mathrm{C}=\mathrm{O})$ of residual ester groups, $1636 \mathrm{~cm}^{-1}(v$ $\mathrm{C}=\mathrm{O}$, strong band), and $1548 \mathrm{~cm}^{-1}(\delta \mathrm{N}-\mathrm{H})$. The loaded PAOx-MIP shows additional signals at $1213 \mathrm{~cm}^{-1}$ and $746 \mathrm{~cm}^{-1}$ confirming the presence of indometacin. Moreover, some differences in the FT-IR absorbance spectra can be observed. First of all, the comparison of IR spectra of loaded PAOx-MIP and PAOx-NIP or unloaded PAOx-MIP in the region around $3500 \mathrm{~cm}^{-1}$ (the region where N-H stretching vibration is observed) showed differences in the signal's structure which lead to assumption that some interaction between the polymer amide groups and indomethacin are formed, presumably hydrogen bonding. Secondly, a new signal at $1093 \mathrm{~cm}^{-1}$ appeared in the loaded PAOx-MIP IR spectrum, which is not present in the PAOx-NIP, the unloaded PAOx-MIP nor the pure indomethacin spectra. This signal is probably the result of interactions formed between the polymer amide groups and the methoxy group of indomethacin. We propose that this signal is a $\mathrm{C}$ O stretching vibration shifted due to formation of interactions with the polymer amide groups. 
Figure 2. FT-IR spectrum of drug unloaded PAOx-MIP, drug loaded PAOx-MIP and PAOx-NIP.

The exemplary SEM images of loaded PAOx-MIP, unloaded PAOx-MIP and PAOx-NIP are presented in Figure 3. All polymers have a uniform, smooth surface, which is probably a result of the high degree of cross-linking. There are no visible differences in the morphology of loaded PAOx-MIP, unloaded PAOx-MIP and PAOx-NIP.

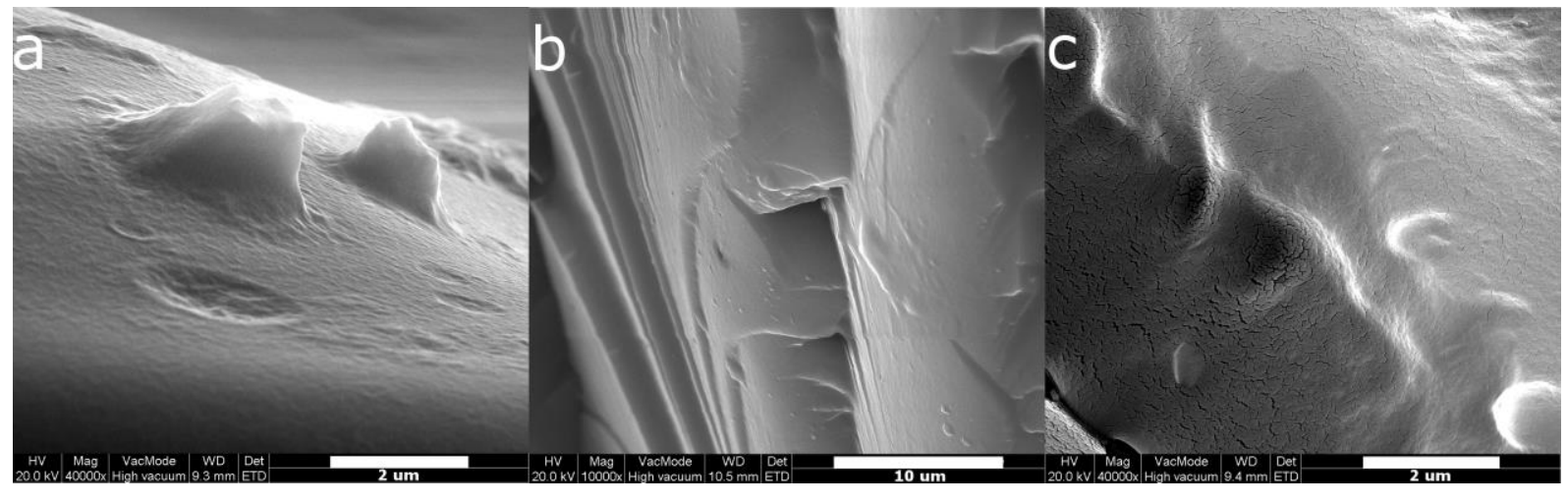

Figure 3. SEM image of (a) drug loaded PAOx-MIP, (b) drug unloaded PAOx-MIP and (c) PAOxNIP. 
The results of thermogravimetric analysis (TGA) of loaded PAOx-MIP, unloaded PAOx-MIP and PAOx-NIP are presented in Figure 4. For all polymers very similar results were obtained and two main steps can be observed. The first one starts at around $80^{\circ} \mathrm{C}$ and ends around $300^{\circ} \mathrm{C}$ and is connected with continuous removal of solvents and water that is enclosed in the crosslinked polymers. The second step in TGA starts at around $300^{\circ} \mathrm{C}$ and ends at around $430^{\circ} \mathrm{C}$ and is connected with the decomposition of the polymer. The mass loss (\%) during this step is slightly lower for the loaded PAOx-MIP compared to the two other polymers, which clearly indicated that some additional non-volatile material is present in the residue. This observation is in accordance with the fact that the polymer contains indometacin in its structure, which is not fully decomposed into volatile material under nitrogen atmosphere.

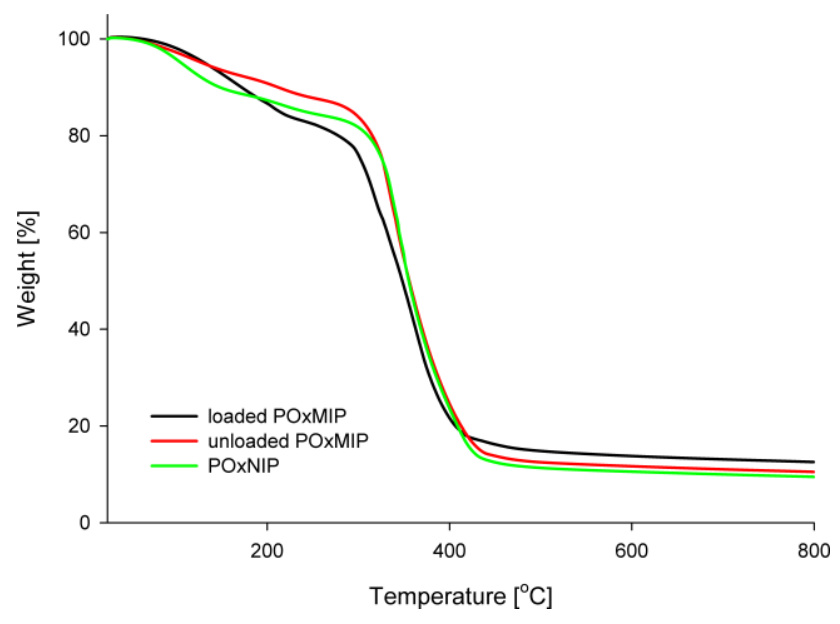

Figure 4. TG results of drug loaded PAOx-MIP, drug unloaded PAOx-MIP and PAOx-NIP.

\subsection{Adsorption isotherms}

Adsorption isotherms are used to characterize the adsorption process of MIPs at the equilibrium state. Figure 5 shows the relationship between the equilibrium concentration of indometacin and 
the amount that is adsorbed by PAOx-MIP or PAOx-NIP. To describe the adsorption process Langmuir and Freundlich adsorption isotherm models were used to fit the experimental data.

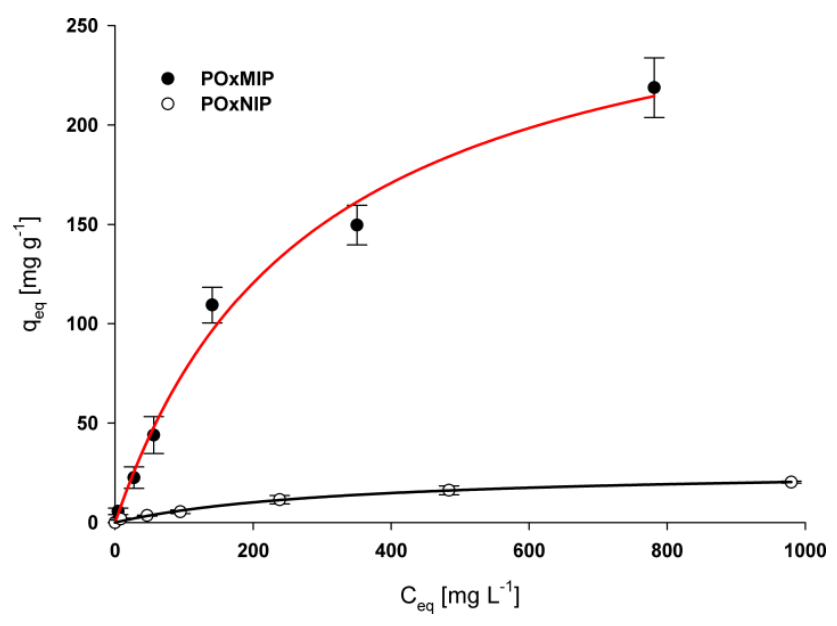

Figure 5. Adsorption isotherms of indometacin onto PAOx-MIP and PAOx-NIP.

The Langmuir adsorption isotherm is mathematically expressed as

$$
\frac{C_{e q}}{q_{e q}}=\frac{C_{e q}}{q_{m}}+\frac{1}{K q_{m}}
$$

where $\mathrm{K}\left(\mathrm{L} \mathrm{mg}^{-1}\right)$ is the binding equilibrium constant, $\mathrm{q}_{\mathrm{m}}\left(\mathrm{mg} \mathrm{g}^{-1}\right)$ is the maximum amount of indometacin bonded, $\mathrm{C}_{\mathrm{eq}}\left(\mathrm{mg} \mathrm{L}^{-1}\right)$ is the equilibrium concentration of indometacin, and $\mathrm{e}_{\mathrm{eq}}\left(\mathrm{mg} \mathrm{g}^{-}\right.$ ${ }^{1}$ ) is the amount of indometacin bonded at the concentration $\mathrm{C}_{\text {eq. }}$. The calculated $\mathrm{K}, \mathrm{q}_{\mathrm{m}}$ and correlation coefficients $\left(\mathrm{R}^{2}\right)$ values are presented in Table 1 . The $\mathrm{R}^{2}$ values obtained for PAOxMIP and PAOx-NIP are 0.974 and 0.956, respectively, which indicates that the experimental data obtained for the PAOx-MIP and PAOx-NIP can be well-described by the Langmuir adsorption model. The $\mathrm{q}_{\mathrm{m}}$ value calculated for the PAOx-MIP is over one order of magnitude higher than the one calculated for PAOx-NIP. This result clearly indicates that the imprinting was successful and 
that molecularly imprinted poly(2-oxazoline)s provide a large potential for developing new MIPs due to their high imprinting properties.

Table 1. Parameters of analyte indometacin adsorption by PAOx-MIP and PAOx-NIP

\begin{tabular}{ccccccc}
\hline \multirow{2}{*}{ Polymer } & \multicolumn{3}{c}{ Langmuir } & \multicolumn{3}{c}{ Freundlich } \\
\cline { 2 - 7 } & $\mathrm{q}_{\mathrm{m}}\left(\mathrm{mg} \mathrm{g}^{-1}\right)$ & $\mathrm{K}\left(\mathrm{L} \mathrm{mg}^{-1}\right)$ & $\mathrm{R}^{2}$ & $\mathrm{~K}_{\mathrm{f}}\left(\mathrm{mg} \mathrm{g}^{-1}\left(\mathrm{~L} \mathrm{mg}^{-1}\right)^{1 / \mathrm{n}}\right)$ & $1 / \mathrm{n}$ & $\mathrm{R}^{2}$ \\
\hline PAOx-MIP & $293 \pm 10$ & $0.003 \pm 0.001$ & 0.974 & $2.14 \pm 0.08$ & $0.72 \pm 0.06$ & 0.980 \\
& & & & & & \\
PAOx-NIP & $25 \pm 2$ & $0.004 \pm 0.001$ & 0.956 & $0.50 \pm 0.06$ & $0.54 \pm 0.05$ & 0.983 \\
& & & & & & \\
\hline
\end{tabular}

The Freundlich adsorption isotherm is mathematically expressed as

$$
\begin{aligned}
& q_{e q}=K_{f} C_{e q}^{1 / n} \\
& \log q_{e q}=\log K_{f}+\frac{1}{n} \log C_{e q}
\end{aligned}
$$

where $\mathrm{K}_{\mathrm{f}}$ and $\mathrm{n}$ represent the Freundlich constants, $\mathrm{C}_{\mathrm{eq}}\left(\mathrm{mg} \mathrm{L}^{-1}\right)$ is the equilibrium concentration of indometacin, and $\mathrm{q}_{\mathrm{eq}}\left(\mathrm{mg} \mathrm{g}^{-1}\right)$ is the amount of indometacin adsorbed at the concentration $\mathrm{C}_{\text {eq. }}$ The calculated $K_{f}, 1 / n$, and correlation coefficient $\left(R^{2}\right)$ values are given in Table 1 . The $R^{2}$ values obtained for PAOx-MIP and PAOx-NIP are 0.980 and 0.983 , respectively, which indicates that especially for the PAOx-NIP the Freundlich isotherm agrees better with experimental data than the Langmuir adsorption model. For the PAOx-MIP the $\mathrm{R}^{2}$ value is almost identical as the one obtained for Langmuir model, which indicates that both models describe the adsorption by PAOx-MIP well. The value of $1 / \mathrm{n}$ ranging between 0 and 1 is a measure of adsorption intensity or surface heterogeneity. The surface is more heterogeneous when the value of $1 / \mathrm{n}$ gets closer to zero. ${ }^{52}$ The values of $1 / \mathrm{n}$ are 0.72 and 0.50 for PAOx-MIP and PAOx-NIP, respectively which indicates that 
the PAOx-NIP has a more heterogeneous surface than PAOx-MIP, which explains why the PAOxNIP has a worse fit with the Langmuir isotherm model.

\subsection{Adsorption kinetics}

The influence of the interaction time on the adsorption capacity was studied to evaluate the adsorption kinetics. Two kinetic models were applied to characterize the adsorption process. The first model is the pseudo-first-order model given by Langergren and Svenska which is expressed as:

$$
\log \left(q_{e}-q_{t}\right)=\log q_{e}-\frac{k_{1}}{2.303} t
$$

where $\mathrm{q}_{\mathrm{e}}$ and $\mathrm{q}_{\mathrm{t}}$ are the amount of substrate adsorbed $\left(\mathrm{mg} \mathrm{g}^{-1}\right)$ at equilibrium and at time $\mathrm{t}(\mathrm{h})$, respectively, and $\mathrm{k}_{1}\left(\mathrm{~h}^{-1}\right)$ is the pseudo-first-order rate constant. The plots of $\log \left(\mathrm{q}_{\mathrm{e}}-\mathrm{q}_{\mathrm{t}}\right)$ versus $\mathrm{t}$ is presented in Figure 6 and the $\mathrm{k}_{1}$ and $\mathrm{R}^{2}$ values are given in Table 2 . The $\mathrm{R}^{2}$ values are relatively high which indicates that the pseudo-first-order model can be applied to describe the kinetics of the adsorption of indometacin onto PAOx-MIP and PAOx-NIP.

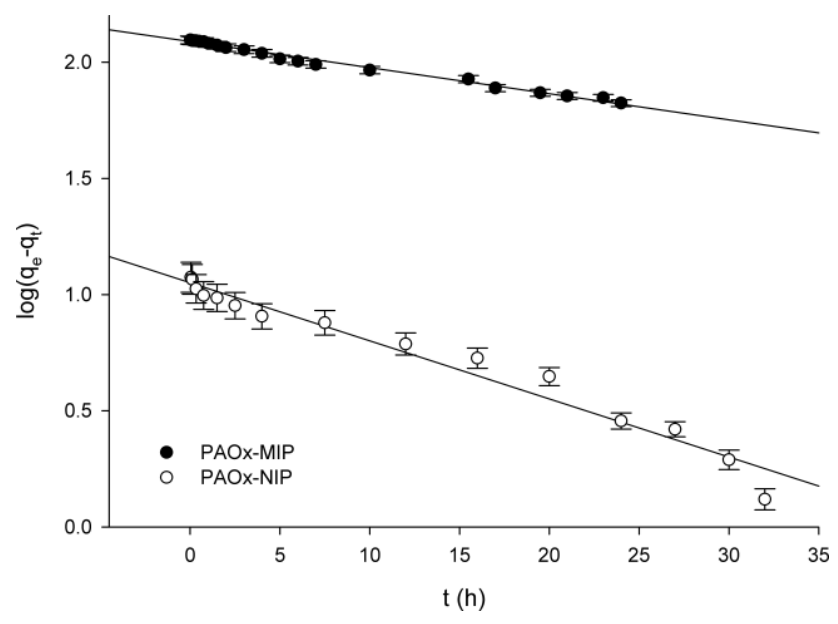

Figure 6. Pseudo-first-order kinetic model for indometacin adsorption onto PAOx-MIP and PAOxNIP. 
Table 2. Kinetic parameters calculated for pseudo-first-order and pseudo-second-order models

\begin{tabular}{ccccc}
\hline & \multicolumn{2}{c}{ Pseudo-first-order } & \multicolumn{2}{c}{ Pseudo-second-order } \\
Polymer & \multicolumn{2}{c}{ kinetic } & \multicolumn{2}{c}{ kinetic } \\
& & & \\
\cline { 2 - 5 } $\mathrm{k}_{1}\left(\mathrm{~h}^{-1}\right)$ & $\mathrm{R}^{2}$ & $\mathrm{k}_{2}\left(\mathrm{~g} \mathrm{mg}^{-1} \mathrm{~h}^{-1}\right)$ & $\mathrm{R}^{2}$ \\
\hline PAOx- & & & & \\
MIP & $0.026 \pm 0.005$ & 0.989 & $0.0003 \pm 0.0001$ & 0.677 \\
PAOx- & & & & \\
NIP & $0.058 \pm 0.006$ & 0.967 & $0.0074 \pm 0.0008$ & 0.936 \\
\hline
\end{tabular}

The second model applied is the pseudo-second-order model based on the equilibrium adsorption which can be mathematically expressed as:

$$
\frac{t}{q_{t}}=\frac{1}{k_{2} q_{e}^{2}}+\frac{1}{q_{e}} t
$$

where $\mathrm{k}_{2}\left(\mathrm{~g} \mathrm{mg}^{-1} \mathrm{~h}^{-1}\right)$ is the pseudo-second-order rate constant. The plots of $\mathrm{t} / \mathrm{q}_{\mathrm{t}}$ versus $\mathrm{t}$ is presented in Figure 7 and the $\mathrm{k}_{2}$ and $\mathrm{R}^{2}$ values are given in Table 2. The $\mathrm{R}^{2}$ value calculated for adsorption of indometacin on PAOx-MIP is very low (0.677) indicating that this model cannot be applied to characterize this adsorption process. The $\mathrm{R}^{2}$ value calculated for adsorption of indometacin on PAOx-NIP is also lower than the one calculated for the pseudo-first-order model. However, for the PAOx-NIP the differences in $\mathrm{R}^{2}$ values between the two theoretical models are not as high as for PAOx-MIP. This result suggests, that the mechanism of adsorption of indometacin on PAOx-MIP and PAOx-NIP is different. 


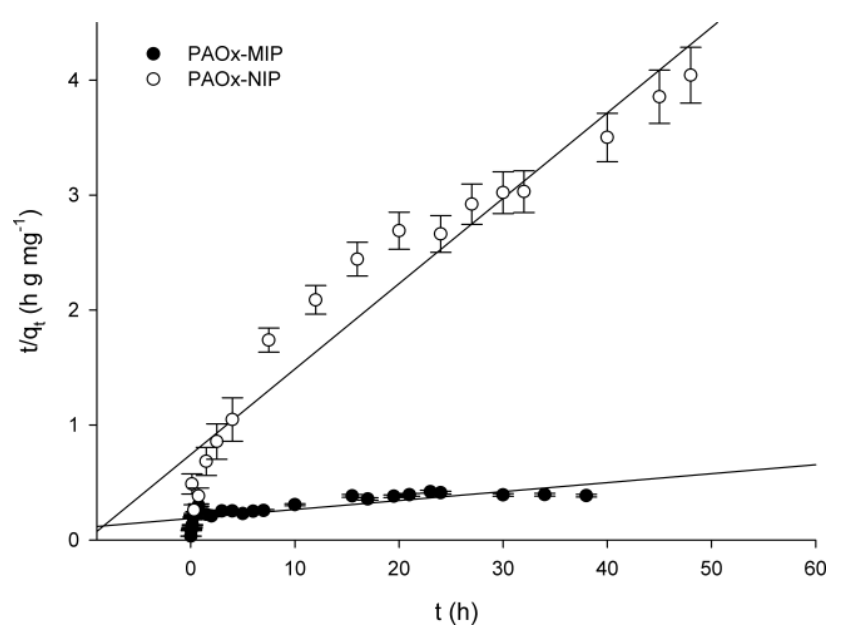

Figure 7. Pseudo-second-order kinetic model for indometacin adsorption onto PAOx-MIP and PAOx-NIP.

\subsection{Adsorption thermodynamics}

Performing adsorption experiments at various temperatures allows to evaluate the thermodynamic parameters such as enthalpy $(\Delta \mathrm{H})$, entropy $(\Delta \mathrm{S})$ and Gibbs free energy $(\Delta \mathrm{G})$ for adsoption. The values of $\Delta \mathrm{H}$ and $\Delta \mathrm{S}$ were calculated using the equation:

$$
\ln K_{d}=\frac{\Delta S}{R}-\frac{\Delta H}{R T}
$$

where $\mathrm{R}\left(8.314 \mathrm{~J} \mathrm{~mol}^{-1} \mathrm{~K}^{-1}\right)$ is the universal gas constant, $\mathrm{T}(\mathrm{K})$ is the temperature at which adsorption occurs and $\mathrm{K}_{\mathrm{d}}$ is the distribution coefficient which is defined as:

$$
K_{d}=\frac{C_{A e}}{C_{e}}
$$

where $\mathrm{C}_{\mathrm{Ae}}$ is the amount adsorbed on solid $\left(\mathrm{mmol} \mathrm{g}^{-1}\right)$ and $\mathrm{C}_{\mathrm{e}}$ is the equilibrium concentration ( $\mathrm{mmol} \mathrm{mL} \mathrm{L}^{-1}$ ). The $\Delta \mathrm{G}$ value was calculated using the equation:

$$
\Delta G=-R T \ln K_{d}
$$

The calculated values of $\Delta \mathrm{H}, \Delta \mathrm{S}$ and $\Delta \mathrm{G}$ are presented in Table 3. For the PAOx-MIP the determined $\Delta \mathrm{H}$ value is negative which means that the adsorption is an exothermic process. On the 
other hand, for the PAOx-NIP the $\Delta \mathrm{H}$ value was found to be positive indicating that the indometacin adsorption on this polymer is an endothermic process, most likely driven by the release of solvating solvent molecules upon adsorption. These results clearly indicates that the mechanism of adsorption for both polymers is different, which is in accordance with other results presented in this study. For both polymers, the $\Delta \mathrm{S}$ values are positive indicating an increase in randomness during the adsorption process due to release of solvent molecules. For the PAOx-NIP this increase is much higher, as the adsorption of indometacin by this polymer is driven by entropy. The overall negative values of $\Delta \mathrm{G}$ indicate that adsorption is spontaneous.

Table 3 Thermodynamic parameters obtained for process of indometacin adsorption

\begin{tabular}{|c|c|c|c|c|c|c|}
\hline \multirow{2}{*}{ Polymer } & \multirow{2}{*}{$\Delta \mathrm{H}\left(\mathrm{kJ} \mathrm{mol}^{-1}\right)$} & \multirow{2}{*}{$\begin{array}{c}\Delta \mathrm{S}\left(\mathrm{J} \mathrm{mol}^{-1}\right. \\
\left.\mathrm{K}^{-1}\right)\end{array}$} & \multicolumn{4}{|c|}{$\Delta \mathrm{G}\left(\mathrm{kJ} \mathrm{mol}{ }^{-1}\right)$} \\
\hline & & & $25\left({ }^{\circ} \mathrm{C}\right)$ & $33\left({ }^{\circ} \mathrm{C}\right)$ & $40\left({ }^{\circ} \mathrm{C}\right)$ & $60\left({ }^{\circ} \mathrm{C}\right)$ \\
\hline POxMIP & $-8.30 \pm 0.35$ & $26.99 \pm 0.52$ & $-16.19 \pm 0.23$ & $-16.61 \pm 0.19$ & $-16.95 \pm 0.26$ & $-17.16 \pm 0.31$ \\
\hline POxNIP & $16.86 \pm 0.48$ & $90.77 \pm 0.84$ & $-9.89 \pm 0.21$ & $-11.07 \pm 0.17$ & $-11.86 \pm 0.24$ & $-13.16 \pm 0.29$ \\
\hline
\end{tabular}

\subsection{Adsorption/desorption cycles}

The reusability of PAOx-MIP was examined in five cycles of adsorption/desorption and the results are summarized in Figure 8. The adsorption capacity of PAOx-MIP after five cycles is still above $90 \%$ of the initial adsorption capacity. This result clearly shows that molecularly imprinted poly(2oxazoline)s can be successfully reused after release of the previously adsorbed molecules. 


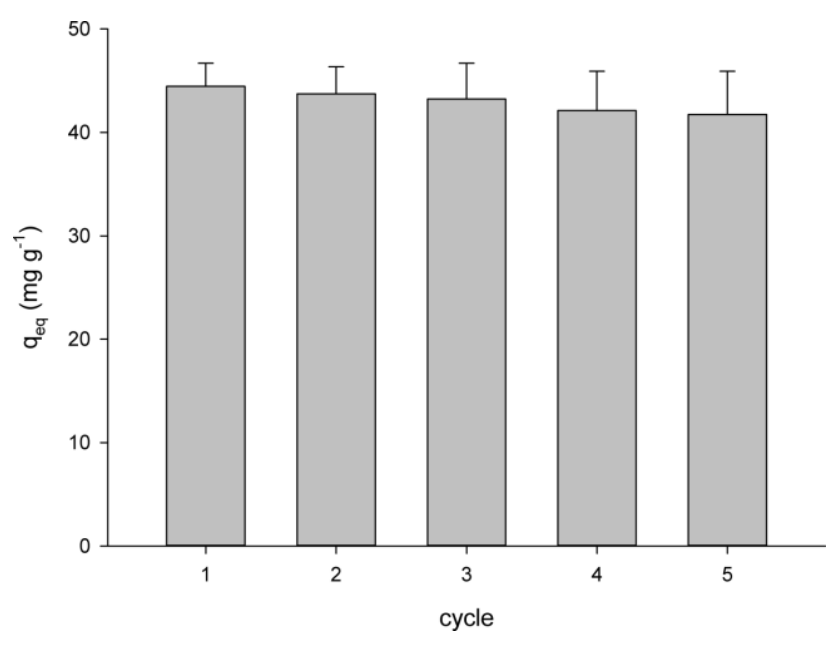

Figure 8. Reusability efficiency of PAOx-MIP for the adsorption of indometacin.

\subsection{In vitro release studies}

The in vitro release studies of indometacin from PAOx-MIP $(50 \mathrm{mg})$ were carried in $50 \mathrm{~mL}$ of PBS (pH 7.4)/EtOH (70:30) solution and $50 \mathrm{~mL}$ of $\mathrm{HCl}-\mathrm{KCl}(\mathrm{pH} 2.0) / \mathrm{EtOH}$ (70:30) solution to study the release behavior in simulated intravenous conditions and gastric fluid, respectively. The release medium was incubated in $37{ }^{\circ} \mathrm{C}$ with constant stirring at $120 \mathrm{rpm}$. At fixed time intervals samples were withdrawn $(200 \mu \mathrm{L})$ and replenished with the same volume of fresh release medium. Introduction of ethanol into the buffer solutions was required to counteract the very low solubility of indometacin in water, which is a common procedure for studying the drug release of poorly soluble drugs. ${ }^{53}$ The indometacin release profiles (Figure 9) demonstrate different behavior depending on the $\mathrm{pH}$ of the release medium. At $\mathrm{pH} 7.4$ the release of indometacin is a steady process which reaches over $90 \%$ release in 4 hours. When the drug-loaded PAOx-MIP was immersed in pH 2.0 buffer, a slower release was observed, but ultimately, a $90 \%$ release was also reached within 5 hours. The slower release at lower $\mathrm{pH}$ may be ascribed to complete protonation of the secondary amine groups, thereby altering the interaction with indometacin, and/or the lower solubility of indomethacin at $\mathrm{pH} 2$ where its carboxylic acid will be protonated. 


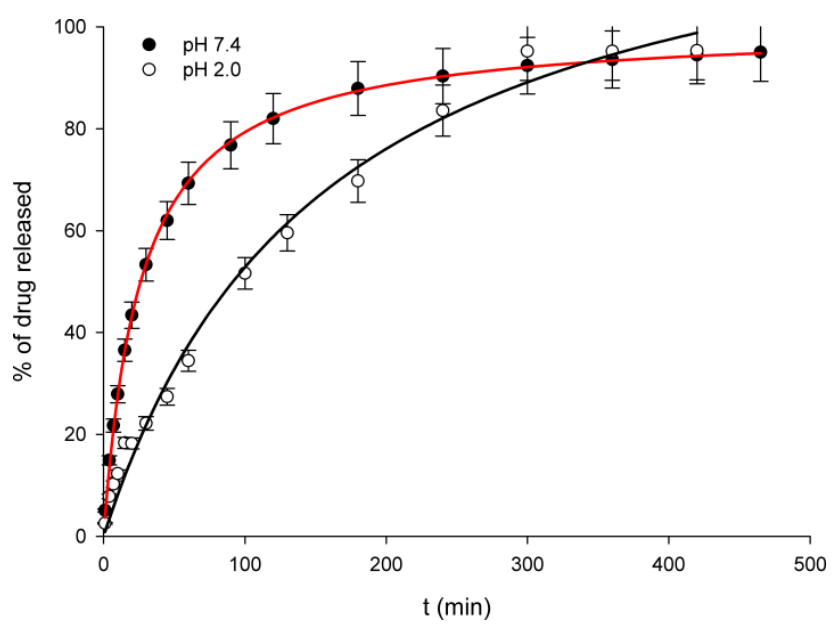

Figure 9. In-vitro release of indometacin from drug-loaded $\mathrm{PAOx}-\mathrm{MIP}$ at $\mathrm{pH}=7.4$ and $\mathrm{pH}=2.0$.

The experimental data obtained from indometacin release was analyzed using several mathematical models, which are applied for characterization of drug release from polymeric materials. The release profiles obtained for $\mathrm{pH} 7.4$ and $\mathrm{pH} 2.0$ were fitted to zero order, first order, Higuchi, and Hixson-Crowell theoretical models. The values of corresponding release constants $\mathrm{k}$ and correlation coefficients $\left(\mathrm{R}^{2}\right)$ are collected in Table 4 . The release of indometacin from the PAOxMIP at $\mathrm{pH} 7.4$ can be partially fitted with Higuchi model $\left(\mathrm{R}^{2}=0.909\right)$, whereas for other release models the $\mathrm{R}^{2}$ values are very low. The Higuchi model is based on Fick's law, therefore it can be assumed that the release mechanism is mostly based on Fickian diffusion. ${ }^{54}$ The release of indometacin from the PAOx-MIP at pH 2.0 is nicely fitted with the Higuchi model $\left(\mathrm{R}^{2}=0.987\right)$. For first order and Hixson-Crowell models, the obtained $\mathrm{R}^{2}$ values are low $(0.658$ and 0.786 , respectively), whereas for the zero order model a moderate $\mathrm{R}^{2}$ value of 0.919 was obtained. This result indicates that the release mechanism is based on Fickian diffusion. Noticeable differences in $\mathrm{R}^{2}$ values for indometacin release at $\mathrm{pH} 7.4$ and 2.0 obtained for the Higuchi model indicates that although both mechanisms are based on Fickian diffusion they are not identical. 
The fact that both release mechanisms are based on Fickian diffusion but they are not identical is probably caused by difference in processes that lead to drug release. At $\mathrm{pH} 7.4$ the solubility of indometacin is higher than at $\mathrm{pH} 2.0$, therefore under these conditions the release of the drug is determined by the kinetics of desorption and diffusion from polymer structure into the solution. ${ }^{55}$ At $\mathrm{pH} 2.0$ the solubility of indomethacin is lower, therefore the initial release is slower than at $\mathrm{pH}$ 7.4. However, the protonation of the amine groups which are responsible for the interactions with drug molecules takes place, which is also dependent on the diffusion of hydronium ions into the polymer structure. As a result, after full protonation the ultimate amount of drug released is higher than for $\mathrm{pH} 7.4$.

Table 4. Release kinetic data of indometacin from drug-loaded PAOx-MIP

\begin{tabular}{ccccccccc}
\hline Buffer & \multicolumn{2}{c}{ Zero order } & \multicolumn{2}{c}{ First order } & \multicolumn{2}{c}{ Higuchi } & \multicolumn{2}{c}{ Hixson-Crowell } \\
\cline { 2 - 8 } $\mathrm{pH}$ & $\mathrm{k}_{0}\left(\mathrm{~h}^{-1}\right)$ & $\mathrm{R}^{2}$ & $\mathrm{k}_{1}\left(\mathrm{~h}^{-1}\right)$ & $\mathrm{R}^{2}$ & $\mathrm{k}_{\mathrm{H}}\left(\mathrm{h}^{-1 / 2}\right)$ & $\mathrm{R}^{2}$ & $\mathrm{k}_{\mathrm{HC}}\left(\mathrm{h}^{-1 / 3}\right)$ & $\mathrm{R}^{2}$ \\
\hline 7.4 & $9.58 \pm 0.43$ & 0.661 & $0.20 \pm 0.08$ & 0.421 & $35.1 \pm 1.2$ & 0.909 & $-0.23 \pm 0.06$ & 0.516 \\
2.0 & $14.2 \pm 0.67$ & 0.919 & $0.37 \pm 0.11$ & 0.658 & $41.1 \pm 1.9$ & 0.987 & $-0.40 \pm 0.08$ & 0.786 \\
\hline
\end{tabular}

\section{Conclusions}

In conclusion, we have shown that molecularly imprinted poly(2-oxazoline)s can be easily synthesized using short side-chain functional poly(2-oxazoline)s and appropriate cross-linking reagents. This new type of MIP was characterized using various analytical techniques and showed satisfactory thermal and chemical stability. Its adsorption properties towards the template indometacin molecules were investigated. The adsorption process was nicely characterized by Langmuir and Freundlich adsorption models, whereas the adsorption process for the non-imprinted polymer followed the Freundlich adsorption model. The maximum calculated amount of 
indometacin bonded for the imprinted polymer was over one order of magnitude higher than the one calculated for non-imprinted. Significant differences for the imprinted and non-imprinted polymer were observed for the adsorption thermodynamics. For the imprinted polymer, adsorption is an exothermic process, whereas for the non-imprinted polymer, adsorption is an endothermic process. These results clearly indicate that the mechanism of adsorption for both polymers is different. Kinetics of adsorption for both polymers was nicely described by the pseudo-first-order kinetic model. The release kinetics of indometacin from drug-loaded imprinted polymer showed that Higuchi model was appropriate to describe the release process at $\mathrm{pH} 7.4$ and 2.0.

In summary, the obtained poly(2-oxazoline) based MIP possesses a large potential for developing a new group of MIPs due to its very high imprinting capacity. The results obtained indicate that molecularly imprinted poly(2-oxazoline)s are a promising materials to be used for biomedical applications.

\section{Corresponding Author}

*E-mail: richard.hoogenboom@ugent.be,

*E-mail: ceglowski.m@gmail.com

\section{Notes}

Conflict of interest: $\mathrm{RH}$ is one of the founders of Avroxa BVBA that commercializes poly(2oxazoline)s as Ultroxa ${ }^{\circledR}$ and is listed as inventor on patent WO2013103297A1 that covers the sidechain amidation that is used in this work.

\section{References}


1. Ye, L.; Mosbach, K., Molecularly imprinted microspheres as antibody binding mimics. React. Funct. Polym. 2001, 48, 149-157.

2. Ye, L.; Haupt, K., Molecularly imprinted polymers as antibody and receptor mimics for assays, sensors and drug discovery. Anal. Bioanal. Chem. 2004, 378, 1887-1897.

3. Vasapollo, G.; Sole, R. D.; Mergola, L.; Lazzoi, M. R.; Scardino, A.; Scorrano, S.; Mele, G., Molecularly Imprinted Polymers: Present and Future Prospective. International Journal of Molecular Sciences 2011, 12, 5908.

4. Çakir, P.; Cutivet, A.; Resmini, M.; Bui, B. T. S.; Haupt, K., Protein-Size Molecularly Imprinted Polymer Nanogels as Synthetic Antibodies, by Localized Polymerization with Multiinitiators. Adv. Mater. (Weinheim, Ger.) 2013, 25, 1048-1051.

5. Gao, B.; An, F.; Zhu, Y., Novel surface ionic imprinting materials prepared via couple grafting of polymer and ionic imprinting on surfaces of silica gel particles. Polymer 2007, 48, 22882297.

6. Takeuchi, T.; Sunayama, H.; Takano, E.; Kitayama, Y., Post-imprinting and In-Cavity Functionalization. In Molecularly Imprinted Polymers in Biotechnology, Mattiasson, B.; Ye, L., Eds. Springer International Publishing: Cham, 2015; pp 95-106.

7. Chen, L.; Xu, S.; Li, J., Recent advances in molecular imprinting technology: current status, challenges and highlighted applications. Chem. Soc. Rev. 2011, 40, 2922-2942.

8. Hennion, M.-C., Solid-phase extraction: method development, sorbents, and coupling with liquid chromatography. J. Chromatogr., A 1999, 856, 3-54.

9. Cegłowski, M.; Smoluch, M.; Reszke, E.; Silberring, J.; Schroeder, G., Molecularly imprinted polymers as selective adsorbents for ambient plasma mass spectrometry. Anal. Bioanal. Chem. 2017, 409, 3393-3405. 
10. Tamayo, F. G.; Turiel, E.; Martín-Esteban, A., Molecularly imprinted polymers for solidphase extraction and solid-phase microextraction: Recent developments and future trends. $J$. Chromatogr., A 2007, 1152, 32-40.

11. Wulff, G., Enzyme-like Catalysis by Molecularly Imprinted Polymers. Chem. Rev. (Washington, DC, U. S.) 2002, 102, 1-28.

12. Zheng, A.-X.; Gong, C.-b.; Zhang, W.-j.; Tang, Q.; Huang, H.-r.; Chow, C.-f.; Tang, Q., An amphiphilic and photoswitchable organocatalyst for the aldol reaction based on a productimprinted polymer. Molecular Catalysis 2017, 442, 115-125.

13. Shaabani, A.; Afshari, R.; Hooshmand, S. E.; Keramati Nejad, M., Molecularly Imprinted Polymer as an Eco-Compatible Nanoreactor in Multicomponent Reactions: A Remarkable Synergy for Expedient Access to Highly Substituted Imidazoles. ACS Sustainable Chemistry \& Engineering 2017, 5, 9506-9516.

14. Haupt, K.; Mosbach, K., Molecularly Imprinted Polymers and Their Use in Biomimetic Sensors. Chem. Rev. (Washington, DC, U. S.) 2000, 100, 2495-2504.

15. Malitesta, C.; Losito, I.; Zambonin, P. G., Molecularly Imprinted Electrosynthesized Polymers: New Materials for Biomimetic Sensors. Anal. Chem. 1999, 71, 1366-1370.

16. Haupt, K., Molecularly imprinted polymers in analytical chemistry. Analyst 2001, 126, 747756.

17. Luliński, P., Molecularly imprinted polymers based drug delivery devices: a way to application in modern pharmacotherapy. A review. Mater. Sci. Eng., C 2017, 76, 1344-1353.

18. Kurczewska, J.; Cegłowski, M.; Pecyna, P.; Ratajczak, M.; Gajęcka, M.; Schroeder, G., Molecularly imprinted polymer as drug delivery carrier in alginate dressing. Mater. Lett. 2017, 201, 46-49. 
19. Zhang, L.-P.; Tang, S.-H.; Mo, C.-E.; Wang, C.; Huang, Y.-P.; Liu, Z.-S., Synergistic effect of liquid crystal and polyhedral oligomeric silsesquioxane to prepare molecularly imprinted polymer for paclitaxel delivery. Eur. Polym. J. 2018, 98, 226-236.

20. Fareghi, A. R.; Moghadam, P. N.; Khalafy, J.; Bahram, M.; Moghtader, M., Preparation of a new molecularly imprinted polymer based on self-crosslinkable cellulose acrylate in aqueous solution: A drug delivery system for furosemide. J. Appl. Polym. Sci. 2017, 134, 45581-n/a.

21. Tiwari, G.; Tiwari, R.; Sriwastawa, B.; Bhati, L.; Pandey, S.; Pandey, P.; Bannerjee, S., Drug delivery systems: An updated review. International Journal of Pharmaceutical Investigation 2012, 2, 2-11.

22. Alvarez-Lorenzo, C.; Concheiro, A., Molecularly imprinted polymers for drug delivery. Journal of chromatography. B, Analytical technologies in the biomedical and life sciences 2004, $804,231-245$.

23. Chien, Y. W.; Lin, S., Optimisation of Treatment by Applying Programmable RateControlled Drug Delivery Technology. Clinical Pharmacokinetics 2002, 41, 1267-1299.

24. Gautam, R.; Singh, R. D.; Sharma, V. P.; Siddhartha, R.; Chand, P.; Kumar, R., Biocompatibility of polymethylmethacrylate resins used in dentistry. Journal of Biomedical Materials Research Part B: Applied Biomaterials 2012, 100B, 1444-1450.

25. Sellergren, B.; Allender, C. J., Molecularly imprinted polymers: a bridge to advanced drug delivery. Adv. Drug Delivery Rev. 2005, 57, 1733-1741.

26. Adams, N.; Schubert, U. S., Poly(2-oxazolines) in biological and biomedical application contexts. Adv. Drug Delivery Rev. 2007, 59, 1504-1520.

27. Schlaad, H.; Diehl, C.; Gress, A.; Meyer, M.; Demirel, A. L.; Nur, Y.; Bertin, A., Poly(2oxazoline)s as Smart Bioinspired Polymers. Macromol. Rapid Commun. 2010, 31, 511-525. 
28. Luxenhofer, R.; Han, Y.; Schulz, A.; Tong, J.; He, Z.; Kabanov, A. V.; Jordan, R., Poly(2oxazoline)s as Polymer Therapeutics. Macromol. Rapid Commun. 2012, 33, 1613-1631.

29. Verbraeken, B.; Monnery, B. D.; Lava, K.; Hoogenboom, R., The chemistry of poly(2oxazoline)s. Eur. Polym. J. 2017, 88, 451-469.

30. Glassner, M.; Vergaelen, M.; Hoogenboom, R., Poly(2-oxazoline)s: A comprehensive overview of polymer structures and their physical properties. Polym. Int. 2018, 67, 32-45.

31. Luxenhofer, R.; Jordan, R., Click Chemistry with Poly(2-oxazoline)s. Macromolecules 2006, 39, 3509-3516.

32. Hoogenboom, R., Poly(2-oxazoline)s: A Polymer Class with Numerous Potential Applications. Angew. Chem., Int. Ed. 2009, 48, 7978-7994.

33. Bauer, M.; Lautenschlaeger, C.; Kempe, K.; Tauhardt, L.; Schubert, U. S.; Fischer, D., Poly(2-ethyl-2-oxazoline) as Alternative for the Stealth Polymer Poly(ethylene glycol): Comparison of in vitro Cytotoxicity and Hemocompatibility. Macromol. Biosci. 2012, 12, 986998.

34. Sedlacek, O.; Monnery, B. D.; Mattova, J.; Kucka, J.; Panek, J.; Janouskova, O.; Hocherl, A.; Verbraeken, B.; Vergaelen, M.; Zadinova, M.; Hoogenboom, R.; Hruby, M., Poly(2-ethyl-2oxazoline) conjugates with doxorubicin for cancer therapy: In vitro and in vivo evaluation and direct comparison to poly[N-(2-hydroxypropyl)methacrylamide] analogues. Biomaterials 2017, $146,1-12$.

35. Raveendran, R.; Mullen, K. M.; Wellard, R. M.; Sharma, C. P.; Hoogenboom, R.; Dargaville, T. R., Poly(2-oxazoline) block copolymer nanoparticles for curcumin loading and delivery to cancer cells. Eur. Polym. J. 2017, 93, 682-694. 
36. Viegas, T. X.; Bentley, M. D.; Harris, J. M.; Fang, Z.; Yoon, K.; Dizman, B.; Weimer, R.; Mero, A.; Pasut, G.; Veronese, F. M., Polyoxazoline: Chemistry, Properties, and Applications in Drug Delivery. Bioconjugate Chem. 2011, 22, 976-986.

37. Luxenhofer, R.; Schulz, A.; Roques, C.; Li, S.; Bronich, T. K.; Batrakova, E. V.; Jordan, R.; Kabanov, A. V., Doubly amphiphilic poly(2-oxazoline)s as high-capacity delivery systems for hydrophobic drugs. Biomaterials 2010, 31, 4972-4979.

38. Persigehl, P.; Jordan, R.; Nuyken, O., Functionalization of Amphiphilic Poly(2-oxazoline) Block Copolymers: A Novel Class of Macroligands for Micellar Catalysis. Macromolecules 2000, 33, 6977-6981.

39. Han, Y.; He, Z.; Schulz, A.; Bronich, T. K.; Jordan, R.; Luxenhofer, R.; Kabanov, A. V., Synergistic Combinations of Multiple Chemotherapeutic Agents in High Capacity Poly(2oxazoline) Micelles. Mol. Pharm. 2012, 9, 2302-2313.

40. Romio, M.; Morgese, G.; Trachsel, L.; Babity, S.; Paradisi, C.; Brambilla, D.; Benetti, E. M., Poly(2-oxazoline)-Pterostilbene Block Copolymer Nanoparticles for Dual-Anticancer Drug Delivery. Biomacromolecules 2018, 19, 103-111.

41. Vlassi, E.; Papagiannopoulos, A.; Pispas, S., Amphiphilic poly(2-oxazoline) copolymers as self-assembled carriers for drug delivery applications. Eur. Polym. J. 2017, 88, 516-523.

42. Moreadith, R. W.; Viegas, T. X.; Bentley, M. D.; Harris, J. M.; Fang, Z.; Yoon, K.; Dizman, B.; Weimer, R.; Rae, B. P.; Li, X.; Rader, C.; Standaert, D.; Olanow, W., Clinical development of a poly(2-oxazoline) (POZ) polymer therapeutic for the treatment of Parkinson's disease - Proof of concept of POZ as a versatile polymer platform for drug development in multiple therapeutic indications. Eur. Polym. J. 2017, 88, 524-552.

43. Morgese, G.; Benetti, E. M., Polyoxazoline biointerfaces by surface grafting. Eur. Polym. J. 2017, 88, 470-485. 
44. Bludau, H.; Czapar, A. E.; Pitek, A. S.; Shukla, S.; Jordan, R.; Steinmetz, N. F., POxylation as an alternative stealth coating for biomedical applications. Eur. Polym. J. 2017, 88, 679-688.

45. Suk, J. S.; Xu, Q.; Kim, N.; Hanes, J.; Ensign, L. M., PEGylation as a strategy for improving nanoparticle-based drug and gene delivery. Adv. Drug Delivery Rev. 2016, 99, 28-51.

46. Verbraeken, B.; Hoogenboom, R., Cyclic Polymers: From Scientific Curiosity to Advanced Materials for Gene Delivery and Surface Modification. Angew. Chem., Int. Ed. 2017, 56, 70347036.

47. Mees, M.; Haladjova, E.; Momekova, D.; Momekov, G.; Shestakova, P. S.; Tsvetanov, C. B.; Hoogenboom, R.; Rangelov, S., Partially Hydrolyzed Poly(n-propyl-2-oxazoline): Synthesis, Aqueous Solution Properties, and Preparation of Gene Delivery Systems. Biomacromolecules 2016, 17, 3580-3590.

48. Rasolonjatovo, B.; Pitard, B.; Haudebourg, T.; Bennevault, V.; Guégan, P., Synthesis of tetraarm star block copolymer based on polytetrahydrofuran and poly(2-methyl-2-oxazoline) for gene delivery applications. Eur. Polym. J. 2017, 88, 689-700.

49. Boerman, M. A.; Roozen, E.; Sánchez-Fernández, M. J.; Keereweer, A. R.; Félix Lanao, R. P.; Bender, J. C. M. E.; Hoogenboom, R.; Leeuwenburgh, S. C.; Jansen, J. A.; Van Goor, H.; Van Hest, J. C. M., Next Generation Hemostatic Materials Based on NHS-Ester Functionalized Poly(2oxazoline)s. Biomacromolecules 2017, 18, 2529-2538.

50. Bouten, P. J. M.; Hertsen, D.; Vergaelen, M.; Monnery, B. D.; Catak, S.; van Hest, J. C. M.; Van Speybroeck, V.; Hoogenboom, R., Synthesis of poly(2-oxazoline)s with side chain methyl ester functionalities: Detailed understanding of living copolymerization behavior of methyl ester containing monomers with 2-alkyl-2-oxazolines. Journal of Polymer Science Part A: Polymer Chemistry 2015, 53, 2649-2661. 
51. Mees, M. A.; Hoogenboom, R., Functional Poly(2-oxazoline)s by Direct Amidation of Methyl Ester Side Chains. Macromolecules 2015, 48, 3531-3538.

52. Haghseresht, F.; Lu, G. Q., Adsorption Characteristics of Phenolic Compounds onto CoalReject-Derived Adsorbents. Energy Fuels 1998, 12, 1100-1107.

53. Manoukian, O. S.; Arul, M. R.; Sardashti, N.; Stedman, T.; James, R.; Rudraiah, S.; Kumbar, S. G., Biodegradable polymeric injectable implants for long-term delivery of contraceptive drugs. J. Appl. Polym. Sci. 2018, 135, 46068-n/a.

54. Paul, D. R., Elaborations on the Higuchi model for drug delivery. Int. J. Pharm. 2011, 418, 13-17.

55. Alhalaweh, A.; Roy, L.; Rodríguez-Hornedo, N.; Velaga, S. P., pH-Dependent Solubility of Indomethacin-Saccharin and Carbamazepine-Saccharin Cocrystals in Aqueous Media. Mol. Pharm. 2012, 9 (9), 2605-2612. 